\title{
Characteristic Enhancement of Blood Pressure V-Shaped Waves in Sinoaortic-Denervated Rats in a Conscious and Quiet State
}

\author{
Huan CHANG ${ }^{1,2,3^{*}}$, Hong-Xia GU ${ }^{4 *}$, Min GONG ${ }^{5}$, Ji-Ju HAN ${ }^{1}$, Yun WANG ${ }^{1}$, Zuo-Li XIA ${ }^{1}$, \\ Xiao-Min ZHAO ${ }^{1,2}$ \\ ${ }^{*}$ These authors contributed equally to this work.
}

${ }^{1}$ Key Laboratory of Atherosclerosis in Universities of Shandong (Taishan Medical University), Taian, China, ${ }^{2}$ Department of Pharmacology, Taishan Medical University, Taian, China, ${ }^{3}$ Department of Pharmacy, Affiliated Hospital of Jining Medical College, Jining, China, ${ }^{4}$ Department of Nephrology, No. 88 Hospital of PLA, Taian, China, ${ }^{5}$ Department of Laboratory Management, Taishan Medical University, Taian, China

Received April 29, 2015

Accepted November 12, 2015

On-line March 15, 2016

\section{Summary}

A hemodynamic feature of chronic sinoaortic-denervated (SAD) rats is the increase in blood pressure variability (BPV) without significant changes in the average level of blood pressure (BP). The current study was designed to investigate the changes in $\mathrm{BP}$ V-shaped waves (V waves) in SAD rats. Sprague-Dawley (SD) rats were divided into 2 groups: SAD rats and sham-operated rats $(n=13)$. Hemodynamics measurements were obtained in conscious, freely moving rats, four weeks after sinoaortic denervation or sham operation. $V$ wave indices were evaluated in rats in both conscious and quiet states. Additionally, normal and high BPV was simulated by the production of $V$ waves with different amplitudes. The results showed that the $\mathrm{V}$ wave amplitude was dramatically increased, with a significantly prolonged duration and reduced frequency in SAD rats. $V$ wave $B P V$ in SAD rats was significantly increased, though BP remained unchanged. The twenty-four hour BPV in all rats was positively correlated with amplitude, duration time and $\mathrm{V}$ wave BPV and negatively correlated with frequency. The systolic BP spectral powers in the low frequency range $(0.38-0.45 \mathrm{~Hz})$ were significantly reduced in the $\mathrm{V}$ waves of SAD rats. Moreover, there was a remarkable increase in mean BPV and a normal mean BP after simulating high BPV in SAD rats. These results suggest that enhancement of $\mathrm{V}$ waves might be a waveform character of $\mathrm{BP}$ in $S A D$ rats in both the conscious and quiet states. These types of $\checkmark$ waves appear to be related to a depression of sympathetic regulation of $\mathrm{BP}$ induced by sinoaortic denervation.

\begin{abstract}
Key words
Rat - Sinoaortic denervation - Nerve • Blood pressure • Blood pressure variability

\section{Corresponding author}

X. M. Zhao, Key Laboratory of Atherosclerosis in Universities of Shandong (Taishan Medical University), No.2 Yingsheng Dong Road, Taian 271000, China. Fax: +86 538 6225275. E-mail: zhaoxiaominty@hotmail.com
\end{abstract}

\section{Introduction}

Increased blood pressure variability (BPV) is an independent risk factor for end-organ damage in hypertension (Parati et al. 2006, Chowdhury et al. 2014, Leoncini et al. 2013, Miao et al. 2006). Animals that have undergone sinoaortic denervation are commonly used as models for studying high BPV. Long-term monitoring of conscious, sinoaortic denervated (SAD) animals has shown increased BPV, with no change in the average level of blood pressure (BP) (Norman et al. 1981, Flues et al. 2012, Sirvente et al. 2014). In fact, studies have suggested that BPV contributes more to end-organ damage than the level of BP itself (Miao et al. 2006). The possible mechanisms for end-organ damage induced by high BPV in SAD animals are direct endothelial lesions (Shen et al. 2006), inflammation (Zhang et al. 2003), oxidative stress (Zhang et al. 2015), renin-angiotensin 
system activation (Miao et al. 2003, Zhang et al. 2011), and increased cardiomyocyte apoptosis (Tao et al. 2004). Because of the marked feature of high BPV in SAD rats, it is reasonable to speculate that high BPV itself produces direct biophysical effects on the body, resulting in dysfunction. Simulating high BPV may be a better way of studying BPV itself; however this requires a more thorough understanding of the BP waveform. BP values were measured on the basis of BP wave recordings. Furthermore, pulse wave analysis was used to assess central aortic pressure. This is helpful when investigating the effect of anti-hypertensive agents on end organs (Avolio et al. 2010, Manisty and Hughes 2013). The four different patterns of the nocturnal BP profile are identified as normal dipping, nondipping, extreme dipping, and reverse dipping. These BP profile patterns are useful for assessing prognosis for organ damage (Afsar et al. 2015, Bendzala et al. 2015, O'Brien et al. 2003, Pickering et al. 2006). However, there is little information regarding BP waveforms in high BPV and substantive knowledge of the $\mathrm{BP}$ waveform characteristic that simulates high BPV is lacking, thus the above speculation has not been examined further.

BPV is regulated by neural (Ramirez et al. 1985, Dai et al. 1997), humoral and vascular factors (Shen and $\mathrm{Su} 2000$ ) and influenced by genetic and environmental factors (Xu et al. 2013). All of these factors ultimately impact the blood vessels in SAD animals. The BP waveforms of these animals may exhibit characteristic changes induced by high BPV; however, changes in BP, when they occur, would be masked in moving animals. Therefore, the aim of this study is to examine whether the BP waveform characteristic appears in SAD rats in both conscious and quiet states. These results may contribute to our knowledge of SAD rats and be useful for simulating high BPV.

\section{Materials and Methods}

\section{Animals}

Male, Sprague-Dawley (SD) rats, weighing 220$250 \mathrm{~g}$, were supplied by Beijing Vital River Laboratory Animal Technology Co., Ltd. Rats were housed in a $12 \mathrm{~h}$ light $/ 12 \mathrm{~h}$ dark cycle at a controlled temperature of $24 \pm 2{ }^{\circ} \mathrm{C}$ and humidity of 45-60\% and had free access to food and water. The Animal Care Ethics Committee of Taishan Medical University (2013004) approved all animal experiments.
Preparation of the SAD rat model and experimental group

Sinoaortic denervation was performed according to the method described by Krieger with minor modifications (Krieger 1964, Liu et al. 2013, Yu et al. 2013). The SD rats were adapted to the housing conditions for 7 days prior to any procedures. Animals were anesthetized with pentobarbital sodium $(40 \mathrm{mg} / \mathrm{kg}$; Merck \& Co., Inc, New Jersey, USA). A midline incision was made on the neck and bilateral sinoaortic denervation was performed. The superior laryngeal was isolated along the vagus nerve and a $5 \mathrm{~mm}$ segment was removed. The common carotid artery and the vagal trunk were isolated, and the rest of the tissue, including the aortic nerve, sympathetic trunk, and arterial sheath tissue were all cut by removing a $5 \mathrm{~mm}$ segment. The superior cervical ganglion was then removed, and the adventitia and its adjacent tissues in the carotid bifurcation were carefully isolated in the direction of the head. A $10 \%$ phenol in ethanol solution was applied to the isolated internal, external, and occipital arteries to remove any residual of nerve endings in the sinus caroticus region.

For the sham operation (Sham) a midline neck incision was made; the neck muscles were isolated bilaterally and phenol was applied to each common carotid artery to control for any potential effects of phenol in SAD rats. Rats were divided into 2 groups: an SAD group $(n=13)$ and a Sham group $(n=13)$. SAD was considered complete when the heart rate decreased by $<20$ beats per minute after a BP elevation of $\geq 50 \mathrm{~mm} \mathrm{Hg}$ after intravenous injection of phenylephrine (2-5 mg/kg). A heart rate decrease of 60-100 beats per minute has been discovered in sham-operated rats (Yu et al. 2013).

\section{Hemodynamic monitoring of conscious rats}

BP and heart rate were continuously recorded in conscious, freely moving rats as previously described (Liu et al. 2013, Yu et al. 2013, Shang et al. 2011, Xie et al. 2003). Briefly, 4 weeks after SAD or sham operations, rats were anesthetized with pentobarbital sodium and a floating catheter (PE10; Biotrol, Paris, France) was inserted into the lower abdominal artery via the left femoral artery; another catheter (PE50) was inserted into the left femoral vein for intravenous injection. After 2 days of recovery, rats were placed in individual cylindrical cages with food and water. A biosignal analytical system (model MPA 2000, 
Shanghai Alcott Biotech Co., Ltd, Shanghai, China) was connected to the arterial catheter to record BP. After a $14 \mathrm{~h}$ habituation, beat-to-beat $\mathrm{BP}$ and heart period (HP) values were acquired online for $24 \mathrm{~h}$. Offline analysis was performed to obtain related hemodynamic parameters. The beat-to-beat BP mean values were used as indexes of $\mathrm{BP}$ and the standard deviations of beat-tobeat BP values as indexes of BPV (Liu et al. 2013, Yu et al. 2013, Shang et al. 2011, Xie et al. 2003).

\section{Determination of arterial baroreflex sensitivity (BRS)}

BRS was measured in conscious rats, after recording normal BP for $24 \mathrm{~h}$, using a previously described method (Smyth et al.1969, Song et al. 2010, $\mathrm{Yu}$ et al. 2013). Briefly, a bolus of phenylephrine (3-5 $\mu \mathrm{g} / \mathrm{kg}$; Sigma Chemical Co., St. Louis, MO, USA.) was administered via the femoral vein and BP was recorded. The dosage of phenylephrine was adjusted to elevate systolic BP (SBP) by $20-40 \mathrm{~mm} \mathrm{Hg}$. There was a delay (about $1 \mathrm{~s}$ ) between the increase in BP (stimulus) and the prolongation of the HP (response). HP (Y-axis) was plotted against SBP (X-axis) for linear regression analysis with 2 to 8 shifts. The slope with the largest correlation coefficient was taken as the BRS $(\mathrm{ms} / \mathrm{mm} \mathrm{Hg})$. The mean of two measurements served as the final result.

\section{Measurement of amplitude, duration time and frequency of $V$ waves}

BP was recorded from 9-11 a.m. A surveillance camera (model 7028, Anni Digital Technology Co., Ltd, Shenzhen, China) was used to watch the rats during BP recording. Rats that did not move or engage in activity for $5 \mathrm{~min}$ were considered to be in a conscious and quiet state. Uncompressed BP of V waves in these rats were selected and analyzed offline using MPA 2000 software (Version 3.04.04.25). An entire V wave was taken as the point at which the BP started to drop until the point at which it was restored to the initial level. The amplitude of a $\mathrm{V}$ wave was represented by the difference between the maximum and minimum BP. The duration was taken as the time at which the BP of V wave started to drop to the time at which it was restored to the initial level. The frequency was calculated as the number of $\mathrm{V}$ waves that appeared in $5 \mathrm{~min}$. The $\mathrm{V}$ wave amplitude and duration time means over 5 min were taken as the final results. In this study, a V wave was considered valid only if the amplitude of diastolic BP (DBP) was more than $10 \mathrm{~mm} \mathrm{Hg}$.

\section{Detection of the hemodynamic parameters of $V$ waves}

The beat-to beat BP and BPV values for the $\mathrm{V}$ waves that appeared over $5 \mathrm{~min}$ in conscious, quiet rats were calculated using MPA 2000 software. The mean values of these parameters were taken as the final results.

\section{Power spectrum analysis of $V$ waves}

The power spectrum of all $\mathrm{V}$ waves that appeared over $5 \mathrm{~min}$ in conscious, quiet rats was analyzed using MPA 2000 software. Calculations of SBP spectral powers in the low frequency (LF: 0.38$0.45 \mathrm{~Hz}$ ) range and $\mathrm{HP}$ spectral powers in the high frequency (HF: 1.04-1.13 Hz) range were performed (Howarth et al. 2005, Cerutti et al. 1991) and mean SBP and HP powers were taken as the final results.

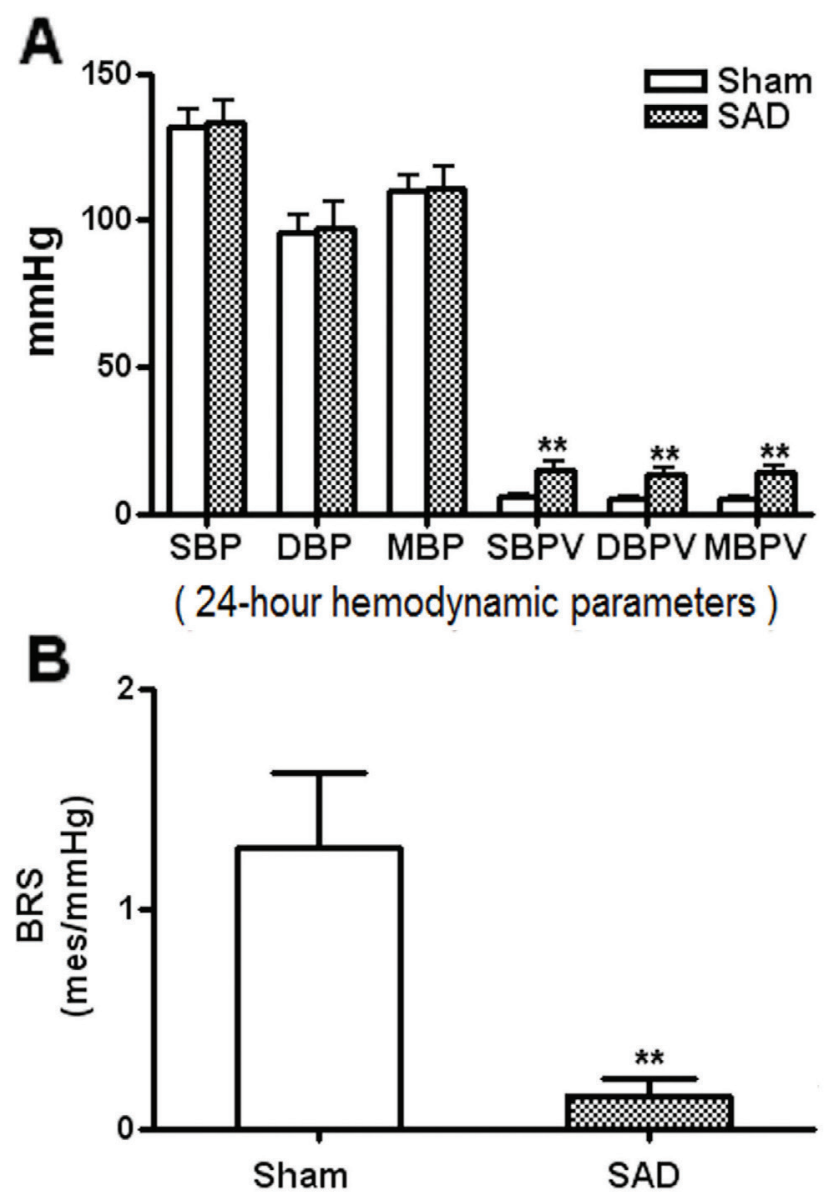

Fig. 1. Hemodynamic changes in $S A D$ and Sham rats over $24 \mathrm{~h}$. (A) A comparison of BP and BPV in SAD and Sham rats. (B) A comparison of BRS in SAD and Sham rats. Values are means $\pm S D(n=13)$. $* * P<0.01$ vs. Sham group 

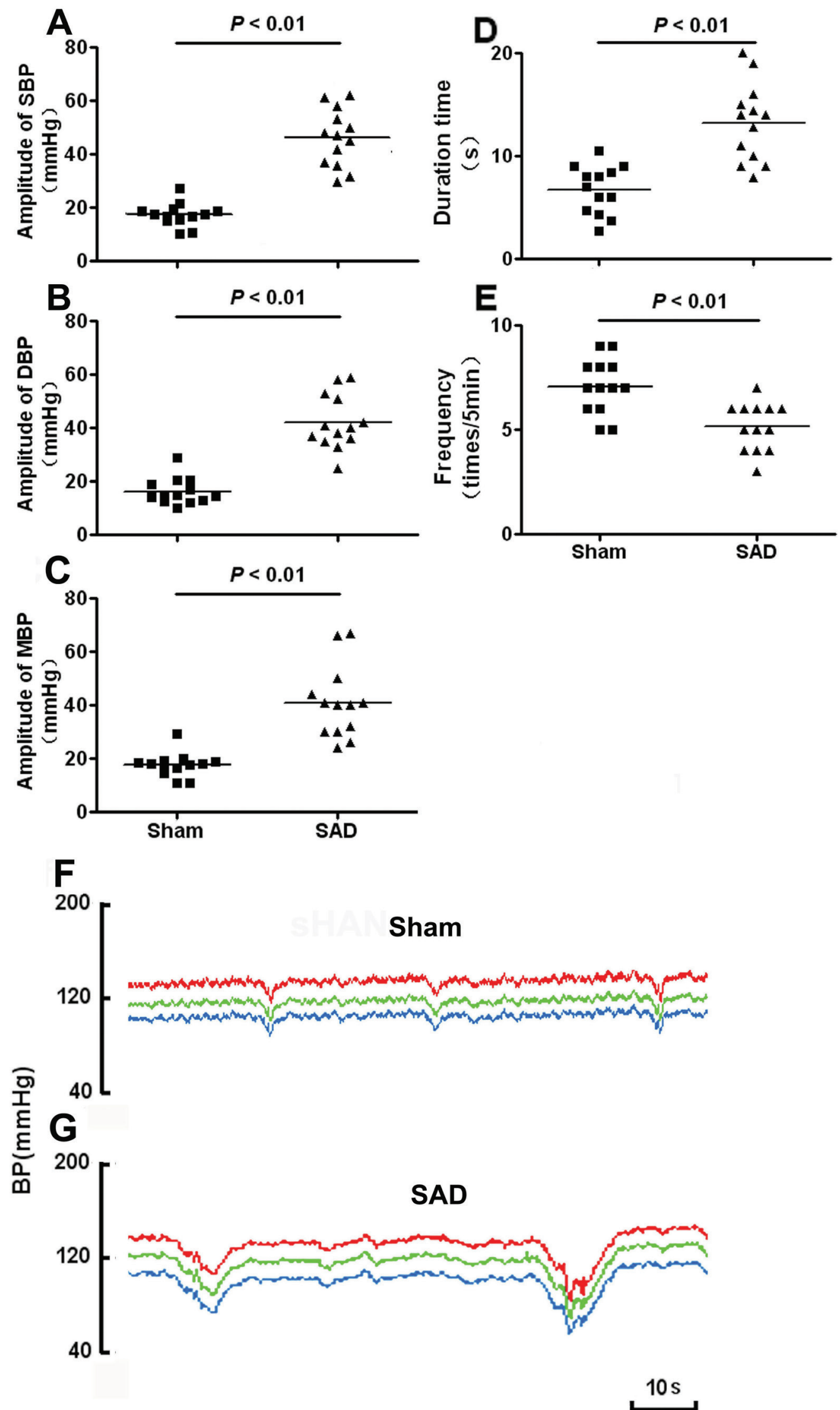

Fig. 2. Amplitude (A, B, C), duration time (D), and frequency (E) of $\vee$ waves and typical $V$ wave diagram in uncompressed state displayed with the MPA 2000 software in Sham (F) and SAD (G) rats. Red (top) represents SBP recording curve. Green (middle) represents MBP recording curve. Blue (bottom) represents DBP recording curve. Values are means $\pm S D(n=13)$. $* * P<0.01$ vs. Sham group 
Table 1. R-values for the correlation between 24-h hemodynamic parameters and the amplitude, duration time and frequency of $V$ waves.

\begin{tabular}{lccccrr}
\hline Variable & SBP & DBP & MBP & SBPV & DBPV & MBPV \\
\hline Amplitude (SBP) & 0.120 & 0.114 & 0.079 & $0.898^{* *}$ & $0.828^{* *}$ & $0.966^{* *}$ \\
Amplitude (DBP) & 0.104 & 0.094 & 0.069 & $0.709^{* *}$ & $0.735^{* *}$ & $0.934^{* *}$ \\
Amplitude (MBP) & 0.144 & 0.156 & 0.139 & $0.544^{* *}$ & $0.781^{* *}$ & $0.887^{* *}$ \\
Duration time & 0.156 & 0.075 & 0.118 & $0.665^{* *}$ & $0.658^{* *}$ & $0.730^{* *}$ \\
Frequency & 0.116 & 0.110 & 0.156 & $-0.801^{* *}$ & $-0.796^{* *}$ & $-0.597^{* *}$ \\
\hline
\end{tabular}

SBP indicates systolic blood pressure; DBP, diastolic blood pressure; MBP, mean blood pressure; SBPV, SBP variability; DBPV, DBP variability; MBPV, MBP variability. $\mathrm{n}=26$ (SAD + Sham). ** $\mathrm{P}<0.01$

\section{Simulation of BPV in SAD and Sham rats}

The simulation system consisted of a flow control pump (model BT-100B, Huxi Instrument Company, Shanghai, China), a pressure roller pump (model PERIPRO-2H-220, Guangzhou Coslan instrument co. Ltd, Guangzhou, China), a pressure variability roller pump (model PERIPRO-2H-220, Guangzhou Coslan instrument co. Ltd, Guangzhou, China) and hemodynamic monitor (model MPA2000, Shanghai Alcott Biotech Co., Ltd, Shanghai, China). Heparinized whole blood from rats was allowed to flow into the simulation system and the pressure pump was used to simulate BP. BPV in Sham rats was simulated by the producing repeated $\mathrm{V}$ waves each with an amplitude of about $15 \mathrm{~mm} \mathrm{Hg}$, a duration times of about $2 \mathrm{~s}$ and a frequency of about 1 wave/5 s. BPV in SAD rats was simulated with repeated $\mathrm{V}$ waves of the same duration and frequency as above, but with amplitudes of approximately $40 \mathrm{~mm} \mathrm{Hg}$. The amplitude, duration, and frequency were adjusted with a pressure variability roller pump ( $\mathrm{n}=4$ simulations). BP results were recorded for 5 min via an MPA 2000 system. Mean BP (MBP) and mean BPV (MBPV) were obtained using the offline analysis detailed above.

\section{Statistical analysis}

Data are presented as means $\pm \mathrm{SD}$. Statistical analysis was performed using SPSS 13.0 (SPSS Inc., Chicago, IL, USA). Comparison of two groups was conducted with a $\mathrm{t}$ test or nonparametric test. Correlation analysis of two variables was performed using linear regression. Statistical significance was accepted at $\mathrm{P}<0.05$.

\section{Results}

Twenty-four-hour hemodynamic data from SAD and Sham rats

Hemodynamic changes were examined over a 24-h period in order to describe the hemodynamic characteristics of SAD rats. SBP, DBP and MBP were not significantly different in SAD compared with Sham rats, however SBPV, DBPV and MBPV were significantly higher in SAD compared to Sham rats $(\mathrm{P}<0.01)$ (Fig. 1). Additionally, BRS was significantly lower in SAD than in Sham rats. Thus, the SAD rats exhibited high BPV with no change in BP, indicating that the SAD model was successfully generated in the current study (Yu et al. 2013, Yang et al. 2011).

Amplitude, duration time, and frequency of $V$ waves in SAD and Sham rats in a conscious and quiet state

The amplitude, duration time, and frequency were measured in order to identify the $\mathrm{V}$ wave characteristics (Figs 2F, 2G) of rats in conscious, quiet states. The amplitude of SBP, DBP, and MBP of $\mathrm{V}$ waves was significantly higher in SAD rats compared to shamoperated rats $(\mathrm{P}<0.01)$. Also, the duration time of $\mathrm{V}$ waves was longer $(\mathrm{P}<0.01)$, and the frequency of $\mathrm{V}$ waves was lower $(\mathrm{P}<0.05)$ in $\mathrm{SAD}$ compared to shamoperated rats (Figs 2A-2E).

Correlation analysis of the 24-h hemodynamic parameters and the amplitude, duration time and frequency of $V$ waves

In both SAD and Sham rats, the 24-h SBPV, DBPV, and MBPV were significantly positively correlated with; the respective amplitudes of SBP, DBP, and MBP in $\mathrm{V}$ waves $(\mathrm{P}<0.01)$ and with the respective duration times of $\mathrm{V}$ waves $(\mathrm{P}<0.01)$ while the $24-\mathrm{h} \mathrm{BPV}$ was strongly negatively correlated with $\mathrm{V}$ wave frequency $(\mathrm{P}<0.01)$. The 24-h SBP, DBP, and MBP were not correlated with any of the respective $\mathrm{V}$ wave parameters above (Table 1). 
Hemodynamic parameters of $V$ waves in SAD and Sham rats

Hemodynamic parameters were examined in $\mathrm{SAD}$ and Sham rats in a conscious and quiet state in order to investigate BP and BPV changes of $\mathrm{V}$ waves. The results showed that the SBPV, DBPV, and MBPV of $\mathrm{V}$ waves in the SAD group were significantly higher $(\mathrm{P}<0.01)$ than in the Sham group, though there was no significant difference in SBP, DBP, and MBP of $\mathrm{V}$ waves between these groups (Fig. 3).

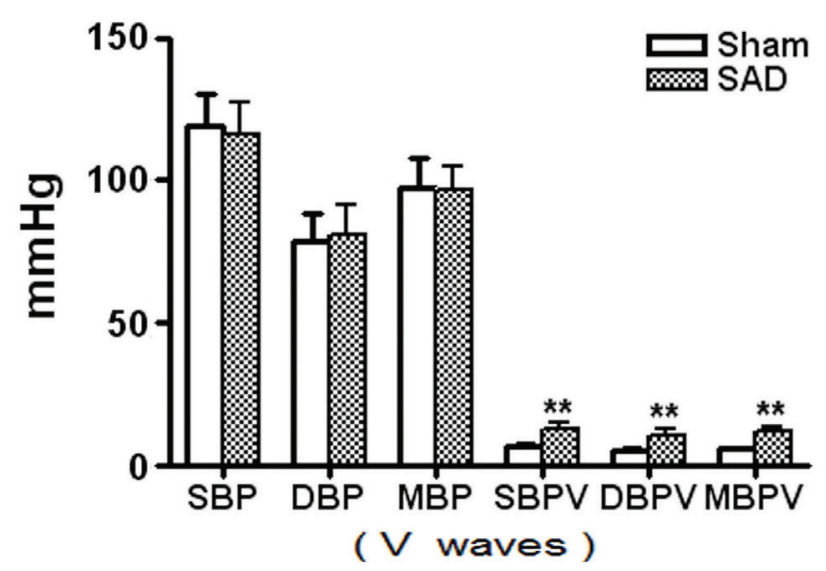

Fig. 3. Hemodynamic changes in $V$ waves of $S A D$ and Sham rats. Values are means $\pm S D(n=13)$. ** $P<0.01$ vs. Sham group

Table 2. $\mathrm{R}$ values for the correlation between the 24-h BP and BPV and the corresponding hemodynamic parameters of $\mathrm{V}$ waves.

\begin{tabular}{ll}
\hline & $\mathbf{R}$ \\
\hline$V-S B P(m m ~ H g)$ & -0.117 \\
$V-D B P(m m ~ H g)$ & -0.166 \\
$V-M B P(m m ~ H g)$ & -0.198 \\
$V-S B P V(m m ~ H g)$ & $0.847^{* *}$ \\
$V-D B P V(m m ~ H g)$ & $0.929^{* *}$ \\
$V-M B P V(m m ~ H g)$ & $0.957^{* *}$ \\
\hline
\end{tabular}

$\mathrm{V}$-SBP indicates systolic BP of $\mathrm{V}$ waves; $\mathrm{DBP}$, diastolic BP of $V$ waves; MBP, mean BP of $V$ waves; SBPV, SBP variability of $V$ waves; DBPV, DBP variability of $V$ waves; MBPV, MBP variability of $\mathrm{V}$ waves. $\mathrm{n}=26$ (SAD + Sham). ${ }^{* *} \mathrm{P}<0.01$

Correlation analysis between 24-h hemodynamic parameters and $B P$ and BPV of $V$ waves in SAD and Sham rats

The 24-h SBPV, DBPV, and MBPV were significantly positively correlated with the SBPV, DBPV, and MBPV of $\mathrm{V}$ waves, respectively, in both SAD and Sham rats, $(\mathrm{P}<0.01)$. However, the 24-h SBP, DBP, and
MBP were not correlated with the SBP, DBP, and MBP of $\mathrm{V}$ waves, respectively (Table 2).

\section{$V$ wave power spectrum changes in SAD and Sham rats}

Power spectrum analysis was performed to describe changes in autonomic nerve function in $\mathrm{V}$ waves of rats in a conscious and quiet state. SBP spectral powers in the LF range decreased markedly in SAD compared with Sham rats (Fig. 4). There were no significant differences in HP spectral powers between $\mathrm{SAD}$ and Sham rats in the HF range.
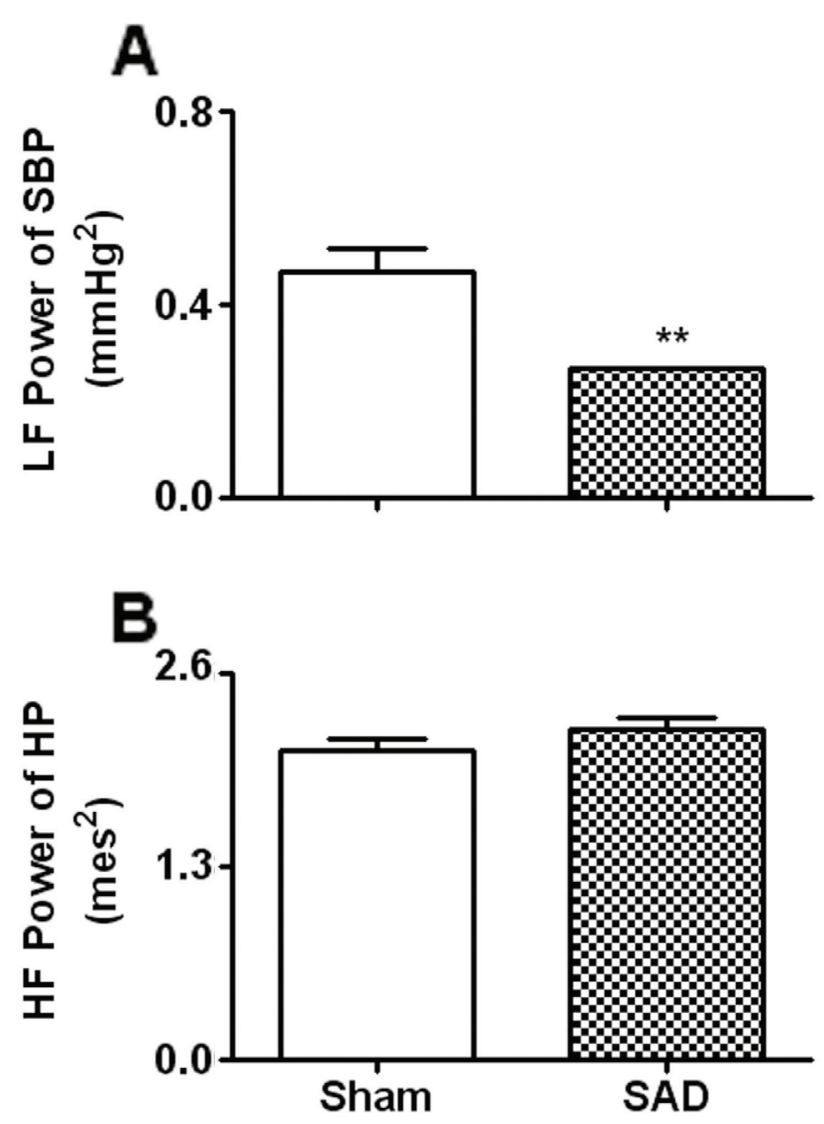

Fig. 4. Power spectrum changes in $V$ waves of $S A D$ and Sham rats. Values are means $\pm S D(n=13) . * * P<0.01$ vs. Sham group

Simulated hemodynamic parameters for SAD and Sham rats

Simulated MBP for SAD rats was almost the same as the simulated MBP for Sham rats (Fig. 5A). However, simulated MBPV for SAD rats was markedly increased compared to that for Sham rats (Fig. 5B).

\section{Discussion}

In this study, it was demonstrated that $\mathrm{V}$ waves 

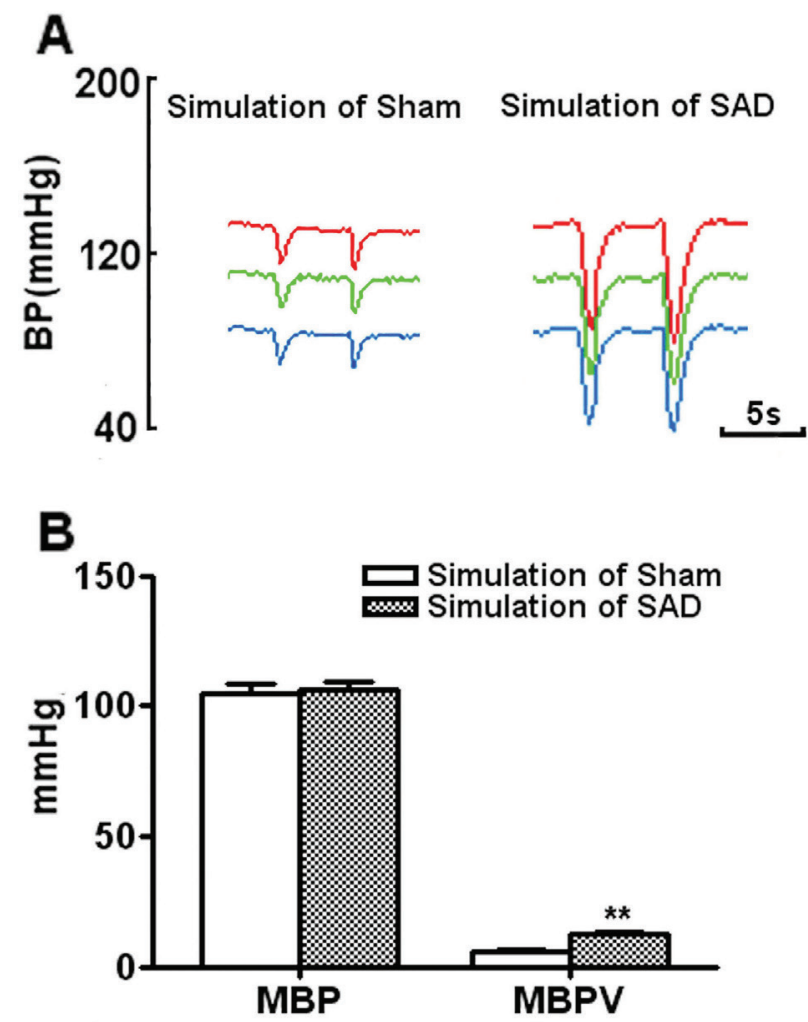

Fig. 5. Simulated hemodynamic changes. (A) Simulated $V$ wave diagram for Sham and SAD rats in uncompressed state displayed with MPA 2000 software. (B) Simulated hemodynamic parameters for Sham and $S A D$ rats. Values are means $\pm S D$ $(n=4) .{ }^{*} \mathrm{P}<0.01$ vs. Simulation of Sham group

are enhanced in conscious, quiet SAD rats. The enhancement of $\mathrm{V}$ waves in these rats was exhibited by larger amplitude, longer duration time, and lower frequency. Moreover, there was high BPV and no change in BP of $\mathrm{V}$ waves in SAD rats. The 24-h BPV and the $\mathrm{V}$ wave BPV were significantly positively correlated in rats. The enhancement of $\mathrm{V}$ waves resulting from sinoaortic denervation may be related to a depression in the sympathetic regulation of BP. Furthermore, simulation of high BPV in SAD rats was produced when the corresponding $\mathrm{V}$ waves were simulated.

Since BP waveform characteristics can be disturbed by activity, the waveforms in this study were observed while rats were in a quiet state. The BP waveforms in conscious, quiet $\mathrm{SAD}$ rats were characterized as enhanced $\mathrm{V}$ waves. This suggests that $\mathrm{V}$ wave enhancement may be a waveform characteristic of $\mathrm{BP}$ in conscious, quiet SAD rats. The following evidence supports the $\mathrm{V}$ wave enhancement observed in this study: First, the V wave amplitude was dramatically increased, the duration time was significantly prolonged and the frequency was obviously reduced in SAD rats. In addition, the 24-h BPV was positively correlated with $\mathrm{V}$ wave amplitude and duration time and negatively correlated with V wave frequency. Second, the SBPV, DBPV, and MBPV of $\mathrm{V}$ waves were significantly increased in SAD rats, however there were no significant changes in SBP, DBP, and MBP of $\mathrm{V}$ waves. Interestingly, these hemodynamic changes in $\mathrm{V}$ waves are consistent with the increased BPV and unchanged BP observed in SAD rats (Mancia and Parati 2003, Xie et al. 2005, Yu et al. 2013, Yang et al. 2011). Moreover, the 24-h BPV was positively correlated with the BPV of $\mathrm{V}$ waves in rats, but was not correlated with BP of $\mathrm{V}$ waves, indicating that the BPV of $\mathrm{V}$ waves reflected the 24-h BPV. Third, simulation of high BPV was achieved when the corresponding $\mathrm{V}$ waves were simulated. On the basis of these findings, all $\mathrm{V}$ wave amplitudes of SBP in conscious, quiet SAD rats were more than $30 \mathrm{~mm} \mathrm{Hg}$. Thus, enhanced $\mathrm{V}$ wave amplitude may be an indicator of successful baroreceptor denervation in SAD rats.

Vagus and sympathetic nerves play important roles in regulating $\mathrm{BP}$ and $\mathrm{HP}$ and alterations in their function can be analyzed with power spectrum analysis. HP spectral powers in the HF (1.04-1.13 Hz) range represent the function of vagus nerves and $\mathrm{BP}$ spectral powers in the LF range $(0.38-0.45 \mathrm{~Hz})$ are generally accepted as a marker of sympathetic modulation (Aubert et al.1999, Pires et al. 2013, Cerutti et al. 1991, Howarth et al. 2005, Yeragani et al. 1998). The power spectrum was further analyzed to describe the production mechanism of $\mathrm{V}$ waves associated with autonomic nerve function. The present study indicated that, the SBP power in the $\mathrm{LH}$ range was reduced in the $\mathrm{V}$ waves of SAD rats whereas the HP power in the HF range showed no significant change. These results suggest that the sympathetic regulation of BP in $\mathrm{V}$ waves was depressed in SAD rats. Therefore, the dysfunction of sympathetic nerves might be one of the reasons for enhancement of $\mathrm{V}$ waves in conscious, quiet $\mathrm{SAD}$ rats.

In summary, these results indicate that enhancement of $\mathrm{V}$ waves may be a waveform characteristic of BP in conscious, quiet SAD rats. This enhancement may be related to depression of the sympathetic regulation of BP induced by sinoaortic denervation. The enhancement of $\mathrm{V}$ waves may add a new feature to SAD rats. Additionally, the $\mathrm{V}$ wave characteristics (an SBP amplitude of more than $30 \mathrm{~mm} \mathrm{Hg}$ ) may be useful for evaluating the success of sinoaortic denervation and simulation of high BPV. 
Future studies are needed to further investigate the mechanism(s) underlying the production of $\mathrm{V}$ waves.

\section{Conflict of Interest}

There is no conflict of interest.

\section{Acknowledgements}

This work was supported by the National Natural Science Foundation of China (81173061), the Excellent Young Research Award Fund of Shandong Province of China (BS2011YY059) and Collaborative Innovation Center for Research and Development of Traditional Chinese Medicine in Mount Tai.

\section{References}

AFSAR B, ELSURER R, KIRKPANTUR A, KANBAY M: Urinary sodium excretion and ambulatory blood pressure findings in patients with hypertension. J Clin Hypertens (Greenwich) 17: 200-206, 2015.

AUBERT AE, RAMAEKERS D, BECKERS F, BREEM R, DENEF C, VAN DE WERF F, ECTOR H: The analysis of heart rate variability in unrestrained rats. Validation of method and results. Comput Methods Programs Biomed 60: 197-213, 1999.

AVOLIO AP, BUTLIN M, WALSH A: Arterial blood pressure measurement and pulse wave analysis - their role in enhancing cardiovascular assessment. Physiol Meas 31: R1-R47, 2010.

BENDZALA M, KRUZLIAK P, GASPAR L, SOUCEK M, MRDOVIC I, SABAKA P, DUKAT A, GASPAROVA I, MALAN L, TAKAZAWA K: Prognostic significance of dipping in older hypertensive patients. Blood Press 24: 103-110, 2015.

CERUTTI C, GUSTIN MP, PAULTARE CZ, LO M, JULIEN C, VINTURAL M, SASSARD J: Autonomic nervous system and cardiovascular variability in rats: a spectral analysis approach. Am J Physiol 261: H1292-H1299, 1991.

CHOWDHURY EK, OWEN A, KRUM H, WING LM, NELSON MR, REID CM; SECOND AUSTRALIAN NATIONAL BLOOD PRESSURE STUDY MANAGEMENT COMMITTEE: Systolic blood pressure variability is an important predictor of cardiovascular outcomes in elderly hypertensive patients. $J$ Hypertens 32: 525-533, 2014.

DAI SM, SHAN ZZ, MIAO CY, YIN M, SU DF: Hemodynamic responses to endothelin-1 and endothelin antagonists microinjected into the nucleus tractus solitarius in rats. J Cardiovasc Pharmacol 30: 475-480, 1997.

FLUES K, MORAES-SILVA IC, MOSTARDA C, SOUZA PR, DINIZ GP, MOREIRA ED, PIRATELLO AC, CHAVES ML, DE ANGELIS K, SALEMI VM, IRIGOYEN MC, CALDINI EG: Cardiac and pulmonary arterial remodeling after sinoaortic denervation in normotensive rats. Auton Neurosci 166: 47-53, 2012.

HOWARTH FC, JACOBSON M, NASEER O, ADEGHATE E: Short-term effects of streptozotocin-induced diabetes on the electrocardiogram, physical activity and body temperature in rats. Exp Physiol 90: 237-245, 2005.

KRIEGER EM: Neurogenic hypertension in the rat. Circ Res 15: 511-521, 1964.

LEONCINI G, VIAZZI F, STORACE G, DEFERRARI G, PONTREMOLI R: Blood pressure variability and multiple organ damage in primary hypertension. J Hum Hypertens 27: 663-670, 2013.

LIU AJ, GUO JM, LIU W, SU FY, ZHAI QW, MEHTA JL, WANG WZ, SU DF: Involvement of arterial baroreflex in the protective effect of dietary restriction against stroke. J Cereb Blood Flow Metab 33: 906-913, 2013.

MANCIA G, PARATI G: The role of blood pressure variability in end-organ damage. J Hypertens Suppl 21: S17-S23, 2003.

MANISTY CH, HUGHES AD: Meta-analysis of the comparative effects of different classes of antihypertensive agents on brachial and central systolic blood pressure, and augmentation index. Br J Clin Pharmacol 75: 79-92, 2013.

MIAO CY, ZHANG LM, YUAN WJ, SU DF: Angiotensin II and AT1 receptor in hypertrophied ventricles and aortas of sinoaortic-denervated rats. Acta Pharmacol Sin 24: 812-818, 2003.

MIAO CY, XIE HH, ZHAN LS, SU DF: Blood pressure variability is more important than blood pressure level in determination of end-organ damage in rats. J Hypertens 24: 1125-1135, 2006.

NORMAN RA Jr, COLEMAN TG, DENT AC: Continuous monitoring of arterial pressure indicates sinoaortic denervated rats are not hypertensive. Hypertension 3: 119-125, 1981. 
O'BRIEN E, ASMAR R, BEILIN L, IMAI Y, MALLION JM, MANCIA G, MENGDEN T, MYERS M, PADFIELD P, PALATINI P, PARATI G, PICKERING T, REDON J, STAESSEN J, STERGIOU G, VERDECCHIA P; EUROPEAN SOCIETY OF HYPERTENSION WORKING GROUP ON BLOOD PRESSURE MONITORING: European Society of Hypertension recommendations for conventional, ambulatory and home blood pressure measurement. J Hypertens 21: 821-848, 2003.

PARATI G, FAINI A, VALENTINI M: Blood pressure variability: its measurement and significance in hypertension. Curr Hypertens Rep 8: 199-204, 2006.

PICKERING TG, SHIMBO D, HAAS D: Ambulatory blood-pressure monitoring. N Engl J Med 354: 2368-2374, 2006.

PIRES W, WANNER SP, LIMA MR, FONSECA IA, FUMEGA U, HAIBARA AS, COIMBRA CC, LIMA NR: Physical exercise performance in temperate and warm environments is decreased by an impaired arterial baroreflex. PLoS One 8: e72005, 2013.

RAMIREZ AJ, BERTINIERI G, BELLI L, CAVALLAZZI A, Di RIENZO M, PEDOTTI A, MANCIA G: Reflex control of blood pressure and heart rate by arterial baroreceptors and by cardiopulmonary receptors in the unanaesthetized cat. J Hypertens 3: 327-335, 1985.

SHANG W, HAN P, YANG CB, GU XW, ZHANG W, XU LP, FU ST, SU DF, XIE HH: Synergism of irbesartan and amlodipine on hemodynamic amelioration and organ protection in spontaneously hypertensive rats. Acta Pharmacol Sin 32: 1109-1115, 2011.

SHEN FM, SU DF: The effect of adenosine on blood pressure variability in sinoaortic denervated rats is mediated by adenosine A2a-receptor. J Cardiovasc Pharmacol 36: 681-686, 2000.

SHEN FM, ZHANG SH, XIE HH, JING Q, WANG DS, SU DF: Early structural changes of aortic wall in sinoaorticdenervated rats. Clin Exp Pharmacol Physiol 33: 358-363, 2006.

SIRVENTE RA, IRIGOYEN MC, SOUZA LE, MOSTARDA C, LA FUENTE RN, CANDIDO GO, SOUZA PR, MEDEIROS A, MADY C, SALEMI VM: Cardiac impairment evaluated by transesophageal echocardiography and invasive measurements in rats undergoing sinoaortic denervation. PLoS One 9: e87935, 2014.

SMYTH HS, SLEIGHT P, PICKERING GW: Reflex regulation of arterial pressure during sleep in man: a quantitative method of assessing baroreflex sensitivity. Circ Res 24: 109-121, 1969.

SONG SW, LIU AJ, BAI C, SU BL, MA XJ, SHEN FM, DUAN JL, SU DF: Blood pressure reduction combining baroreflex restoration for stroke prevention in hypertension in rats. Front Pharmacol 1: 6, 2010.

TAO X, ZHANG SH, SHEN FM, SU DF: High-level apoptosis is persistent in myocardiocytes of sinoaortic-denervated rats. J Hypertens 22: 557-563, 2004.

XIE HH, MIAO CY, LIU JG, SU DF: Effects of long-term treatment with candesartan on organ damages in sinoaortic denervated rats. J Cardiovasc Pharmacol 41: 325-331, 2003.

XIE HH, SHEN FM, CAO YB, LI HL, SU DF: Effects of low-dose ketanserin on blood pressure variability, baroreflex sensitivity and end-organ damage in spontaneously hypertensive rats. Clin Sci (Lond) 108: 547-552, 2005.

XU X, DING X, ZHANG X, SU S, TREIBER FA, VLIETINCK R, FAGARD R, DEROM C, GIELEN M, LOOS RJ, SNIEDER H, WANG X: Genetic and environmental influences on blood pressure variability: a study in twins. J Hypertens 31: 690-697, 2013.

YANG ZW, LI DJ, LIU C, HAN P, YANG YL, SU DF, SHEN FM: Role of vascular K(ATP)channels in blood pressure variability after sinoaortic denervation in rats. Acta Pharmacol Sin 32: 194-200, 2011.

YERAGANI VK, SOBOLEWSKI E, JAMPALA VC, KAY J, YERAGANI S, IGEL G: Fractal dimension and approximate entropy of heart period and heart rate: awake versus sleep differences and methodological issues. Clin Sci (Lond) 95: 295-301, 1998.

YU JG, SONG SW, SHU H, FAN SJ, LIU AJ, LIU C, GUO W, GUO JM, MIAO CY, SU DF: Baroreflex deficiency hampers angiogenesis after myocardial infarction via acetylcholine- $\alpha 7$-nicotinic $\mathrm{ACh}$ receptor in rats. Eur Heart J 34: 2412-2420, 2013.

ZHANG C, CHEN H, XIE HH, SHU H, YUAN WJ, SU DF: Inflammation is involved in the organ damage induced by sinoaortic denervation in rats. J Hypertens 21: 2141-2148, 2003.

ZHANG L, LI F, ZHI G, ZHANG B, CHEN YD: NADPH oxidase contributes to the left ventricular dysfunction induced by sinoaortic denervation in rats. Free Radic Res 49: 57-66, 2015. 
ZHANG LC, LI ZZ, YU YS, WANG ZB, WEI X, SU DF, LI L: Angiotensin-converting enzyme and angiotensinconverting enzyme 2 are involved in sinoaortic denervation-induced cardiovascular hypertrophy in rats. Biol Pharm Bull 34: 1398-1403, 2011. 